\title{
Breccia interlayer effects on steam-assisted gravity drainage performance: experimental and numerical study
}

\author{
Qichen Zhang ${ }^{1} \cdot$ Xiaodong Kang $^{1} \cdot$ Huiqing Liu $^{2} \cdot$ Xiaohu Dong $^{2} \cdot$ Jian Wang $^{1}$
}

Received: 3 August 2021 / Accepted: 28 September 2021 / Published online: 15 October 2021

(c) The Author(s) 2021

\begin{abstract}
Currently, the reservoir heterogeneity is a serious challenge for developing oil sands with SAGD method. Nexen's Long Lake SAGD project reported that breccia interlayer was widely distributed in lower and middle part of reservoir, impeding the steam chamber expansion and heated oil drainage. In this paper, two physical experiments were conducted to study the impact of breccia interlayer on development of steam chamber and production performance. Then, a laboratory scale numerical simulation model was established and a history match was conducted based on the 3D experimental results. Finally, the sensitivity analysis of thickness and permeability of breccia layer was performed. The influence mechanism of breccia layer on SAGD performance was analyzed by comparing the temperature profile of steam chamber and production dynamics. The experimental results indicate that the existence of breccia interlayer causes a thinner steam chamber profile and longer time to reach the peak oil rate. And, the ultimate oil recovery reduced $15.8 \%$ due to much oil stuck in breccia interlayer areas. The numerical simulation results show that a lower permeability in breccia layer area has a serious adverse impact on oil recovery if the thickness of breccia layer is larger, whereas the effect of permeability on SAGD performance is limited when the breccia layer is thinner. Besides, a thicker breccia layer can increase the time required to reach the peak oil rate, but has a little impact on the ultimate oil recovery.
\end{abstract}

Keywords Steam-assisted gravity drainage (SAGD) · Breccia interlayer · Three-dimensional physical simulation · SAGD performance $\cdot$ Oil sand reservoirs

\section{Introduction}

The steam-assisted gravity drainage (SAGD) technology was firstly proposed by Butler (1981) for enhancing heavy oil recovery. In a few decades, SAGD technology has been successfully applied to recover heavy oil reservoirs and oil sands (Baghernezhad and Siavashi 2019; Dong et al. 2019; Zhang et al., 2020; Gates and Chakrabarty 2006). However, this advantageous technology is being challenged as the complexity of reservoir heterogeneity such as barrier layers. Barrier interlayers have a significant impact on SAGD

Qichen Zhang

zhangqch13@cnooc.com.cn

$\bowtie$ Huiqing Liu

1 CNOOC Research Institute Co., Ltd, Beijing 100028, China

2 State Key Laboratory of Petroleum Resources and Prospecting, China University of Petroleum, Beijing 102249, China performance and the influence degree is affected by their location and continuity in the reservoir (Kumar and Hassanzadeh 2021). To understand the fluid flow behaviors and the steam chamber expansion characteristics with barriers, some studies have been conducted by experimental and numerical simulation.

As early as 1992, Yang and Butler (1992) conducted 2D experiments to study the effects of different horizontal layers on oil production. They found that short horizontal barriers did not affect the ultimate oil recovery. The longer horizontal barriers decreased the peak oil production rate, especially when the long barriers were distributed in the middle part of reservoir. But, the research is only focus on the continuous shale barriers. Pooladi-Darvish and Mattar (2002) investigate the influence of barrier layer continuity on SAGD performance in the presence of a gas cap and top water. They concluded that barriers continuity can influence the production performance largely and the sealing barrier case had a best performance due to the steam had no contact with gas cap or water zone reducing the heat loss. Although 
this study indirect reflected the effect of barriers, it provided a deep understanding about the role of barriers. Then, Chen et al. (2007) used a stochastic model with a two-flow region, near well region (NWR) and above well region (AWR), to investigate the influence of reservoir heterogeneities on SAGD. Through adjusting the length of barriers and shale percentage in AWR, they concluded that a shorter barrier length has little effect on oil recovery because the steam can bypass the discrete and small barriers and when the shale percentage higher than $50 \%$, the oil recovery factor has a significant decrease. Ipek et al. (2008) established numerical models to investigate on the lateral shale barrier effects on SAGD performance. The simulated shale barriers cases were similar with Chen's (2007). They changed the shale percentage from 10 to $25 \%$, and the simulation results showed that the production reduced from 18.8 to $74 \%$. They also proposed the permeability enhancement was useless for the shale layered reservoirs because the high heat loss caused by the heated oil and steam bypassing the barriers.

Based on previous research, a new three-dimensional numerical model was established by Le Ravalec et al. (2009) for investigating the effects of shale heterogeneity on SAGD. They concluded that the effect of barriers on SAGD performance up to the distance between the barrier and well pairs. They also suggested that recovery performance was the worst if the shale barrier located between the injector and producer. Shin et al. (2009) built another numerical model based on shale barrier layer parameters form Cold Lake reservoir. They proposed two types of models, which named type A (no flow path between injector and producer) and type B (a flow path between injector and producer), for observing the effect of flow path between well pairs. The results showed the impact of type A is larger than that of type B and the impact can neglect when the size of shale barrier is small (less than $5 \mathrm{~m}$ ). Later, Li et al. (2011) studied effect of different sizes of barriers above the injector using 2D simulation. They found that the flow resistance along the barriers and the extra heat consumption were the major reasons for the barrier effects. Dang et al. (2013) conducted numerical study for evaluating the applicability of SAGD in complex reservoir with shale barriers. The simulation showed only the long continuous shale barriers located in near well region impacts the performance largely. In order to reduce shale barriers impact, Gao et al. (2016) presented a new approach to develop thin reservoir with shale barriers by combining gravity drainage and steam flooding. A threedimensional physical simulation was conducted to simulate the effect of barrier. They suggested the combination of SAGD and steam flooding method can achieve a higher recovery when continuous barrier above the well pairs. These studies on shale barrier effects were aiming at single barrier, but the multiple shale barrier influence mechanism were still unknown and needed further investigate.

In recent years, Xia et al. (2018) studied the effect of multiple interlayer on production performance and steam chamber using experimental and numerical simulation. The results showed the multiple interlayer extended the steam chamber lateral expansion phase and double production peaks. On the basis of that, Huang et al. (2019) presented a 2D visual experimental and numerical study to analyze the multiple interlayer impact on production. They concluded that the length and permeability of the first interlayer had the greatest effect on production. Zhang et al. (2020) established a numerical model considering the shale barrier for validating the influence mechanism. They believed that barriers with rational location far away from injector has positive effect on recovery performance. Currently, with the artificial intelligence (AI) technology rising, data-driven modeling is another rapidly developing prediction method applying for oilfield development industry. The SAGD performance under impact of interlayers was estimated using data analytics and machine learning in several papers (Kim and Shin 2018, 2020; Zheng et al. 2018, 2019; Wang and Leung 2015; Ma and Leung 2018).

Although many scholars have investigated the influence of barrier layers, most of them focused on the impermeable shale barriers above well pairs region. However, with the developing the Long-lake SAGD project, log analyses and core experiments revealed that the breccia barriers are widely and discontinuously distributed in the lower and middle part of the oil sands reservoirs. Besides, the permeability between the breccia barriers is lower than that of homogeneous reservoir part due to irregular breccia shapes and sedimentation. But, research focusing on the influence of breccia barrier layers remains limited and the recovery mechanisms of SAGD under breccia barriers are still not clear. Therefore, it is urgent to understand the influence mechanism of breccia barrier layers on SAGD performance and conduct the quantitative analysis of the breccia layers impact.

In this study, two groups of 3D physical simulations (breccia interlayer and homogeneous) are designed for investigating the effects of breccia layers during SAGD process. The breccia layer influence mechanism was analyzed through comparing with result of two experiments. Then, a laboratory scale numerical model was established for analyzing the influence mechanism under different experimental parameters. Furthermore, the history matching of experimental results was conducted to validate the numerical model. Finally, the impact mechanism of thickness and permeability of breccia layers on SAGD performance were analyzed in detail. 


\section{Physical simulation experiment}

\section{Experiment design}

\section{Experimental parameters}

To study the effects of the breccia layer on SAGD performance, the parameters in field-scale should be convert into the laboratory scale using similarity criteria (Kimber and Farouq Ali 1991; Doan and Farouq Ali 1992; Joshi 1986) before the experiment. Therefore, the actual reservoir parameters were converted to laboratory scale using Eqs. (1) and Eqs. (2) (Butler 1985)

$B_{3}=\sqrt{\frac{\mathrm{k} g H}{\alpha \phi \Delta S_{o} m v_{s}}}$

$\mathrm{t}_{D}=\frac{t}{L} \sqrt{\frac{k g \alpha}{\phi \Delta S_{o} m v_{s} H}}$

where $B_{3}$ is a dimensionless constant; $H$ is the reservoirs thickness; $k$ is the reservoir permeability; $g$ is the gravity constant; $\alpha$ is the reservoir thermal diffusivity coefficient; $\Delta S_{o}$ is the difference between initial and residual oil saturation; $\varphi$ is the porosity; $v_{s}$ is the kinematic oil viscosity under injected steam temperature; $m$ is dimensionless viscositytemperature coefficient. $t_{D}$ is dimensionless time; $t$ is the production time; $L$ is the well pairs spacing.
It is difficult to make all experimental parameters following the similarity criterion due to the limitations of laboratory conditions. Therefore, the heat transfer process and main driving force (gravity) were as the key similarity parameters. The parameters of physical model and the actual oil field that is collected from Long-lake project, as shown in Table.1.

\section{Distribution of breccia layer}

The breccia interlayers are common for the Long-lake oil sands as presented in Fig. 1, and they are distributed in the lower-middle part of oil sands according to the field core data, which cause a low permeability area. When the producer or/and injector is/are located in breccia layer, the low permeability zone, however, will influence the SAGD

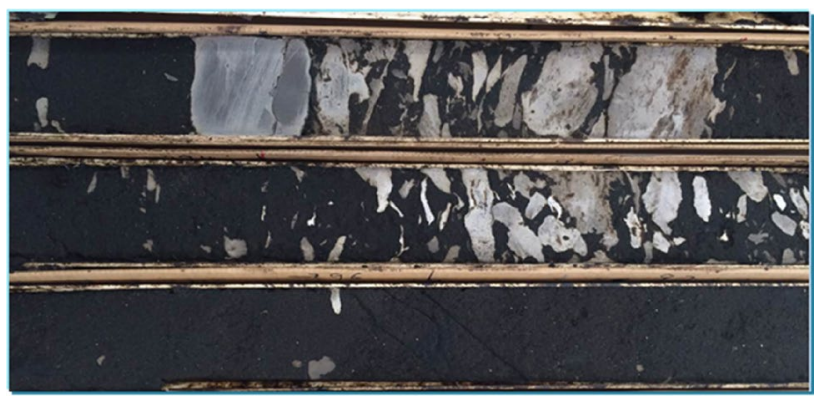

Fig. 1 Core data from Long-lake oil sands
Table 1 Parameters of experiment

\begin{tabular}{|c|c|c|c|}
\hline & Parameters & prototype & model \\
\hline \multirow[t]{15}{*}{ Basic parameters } & Reservoir thickness $(\mathrm{m}, \mathrm{cm})$ & 30 & 12 \\
\hline & Distance between injector and producer $(\mathrm{m}, \mathrm{cm})$ & 5 & 2.5 \\
\hline & Well radius $(m, \mathrm{~cm})$ & 0.1 & 0.6 \\
\hline & Well length $(\mathrm{m}, \mathrm{cm})$ & 800 & 40 \\
\hline & Distance between producer and the bottom $(\mathrm{m}, \mathrm{cm})$ & 3 & 1.2 \\
\hline & Breccia layer thickness $(\mathrm{m}, \mathrm{cm})$ & 10 & 4 \\
\hline & Breccia particle size $(m, \mathrm{~cm})$ & $>1$ & $\begin{array}{l}\text { Diameter } 4 \\
\text { Thickness } 1.5\end{array}$ \\
\hline & Breccia permeability $\left(\mu m^{2}\right)$ & $20 \times 10^{-3}$ & $200 \times 10^{-3}$ \\
\hline & Porosity $(\%)$ & 33 & 37 \\
\hline & Reservoir permeability $\left(\mu m^{2}\right)$ & 5 & 40 \\
\hline & Oil viscosity $(m P a \cdot s)$ & $100 \times 10^{4}$ & $100 \times 10^{4}$ \\
\hline & Reservoir temperature $\left({ }^{\circ} \mathrm{C}\right)$ & 7 & 20 \\
\hline & Steam temperature $\left({ }^{\circ} \mathrm{C}\right)$ & 210 & 210 \\
\hline & Steam quality (\%) & 80 & 80 \\
\hline & Initial reservoir pressure $(M P a)$ & 2.5 & 2.5 \\
\hline \multirow[t]{4}{*}{ SAGD } & Steam chamber pressure $(M P a)$ & 2.0 & 2.0 \\
\hline & Production time $(a, \min )$ & 1 & 59.5 \\
\hline & Preheating time $(a, \min )$ & 0.5 & 30 \\
\hline & Steam injection rate $\left(\mathrm{m}^{3} / \mathrm{d}, \mathrm{mL} / \mathrm{min}\right)$ & 250 & 30 \\
\hline
\end{tabular}




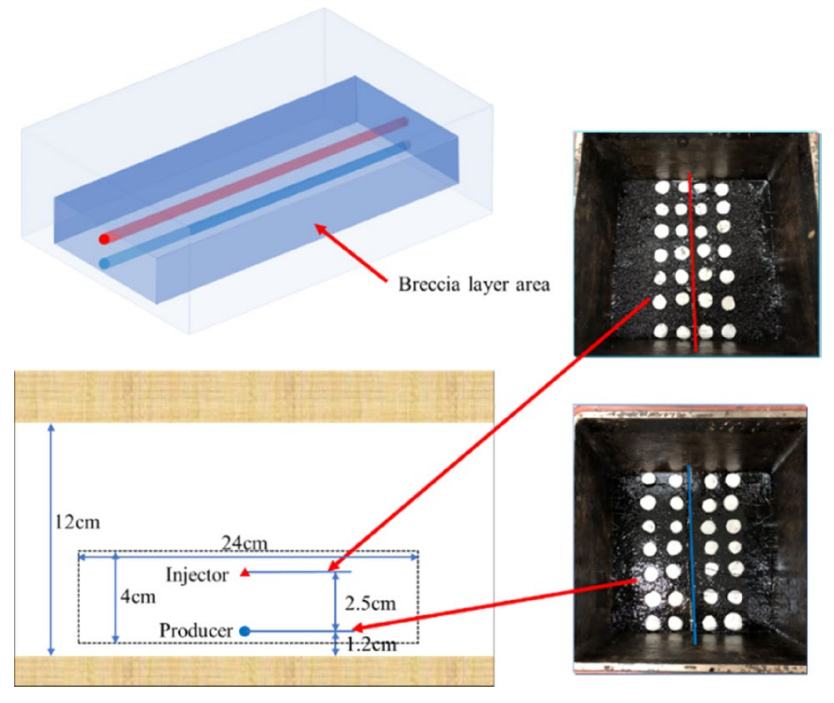

Fig. 2 Schematic of the experimental design

Table 2 Experiment schemes

\begin{tabular}{ll}
\hline Experiments & Model pattern \\
\hline 1 & Homogeneous \\
2 & Breccia interlayer \\
\hline
\end{tabular}

performance. Therefore, to study the breccia interlayer area effects on SAGD performance, an ideal breccia interlayer distribution is designed as shown in Fig. 2. The injector and producer are both in the breccia layer area, where has two staggered distribution breccia interlayers. A homogeneous experiment was also designed. Then, the comprehensive effects of breccia interlayer on SAGD performance can be qualitative analyzed through comparison. Table. 2 shows the conditions of the two patterns.

\section{Experimental materials}

The main experimental materials as follow:

(1) Sand: The 20-mesh quartz sand were used to fill the model. The sands were cleaned up and screened the impurities before filling.

(2) Oil sample: The oil sample for these SAGD experiments was collected from Long-lake block, Canada. The oil viscosity is $100 \times 10^{4} \mathrm{mPa} \cdot \mathrm{s}$ at $20^{\circ} \mathrm{C}$. The relationship of oil viscosity and temperature is shown in Fig. 3.

(3) Breccia interlayer: Based on the core data from Longlake project as presented in Fig. 1, cement was selected to simulate the breccia as presented in Fig. 4 because its thermophysical property and permeability are similarity with breccia.

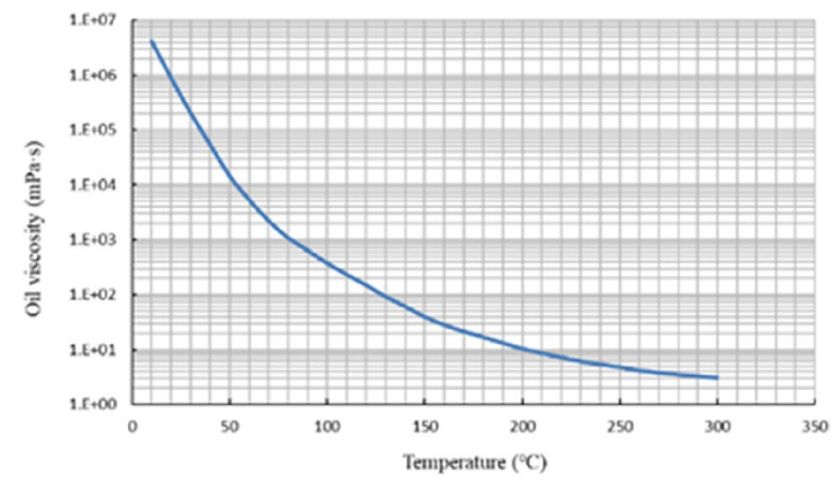

Fig. 3 Oil viscosity versus temperature curve

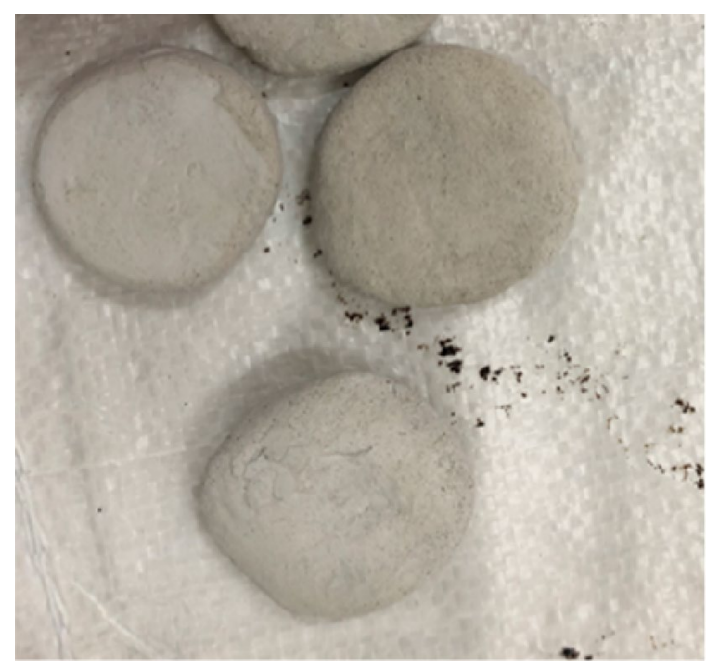

Fig. 4 Simulated breccia in laboratory scale

\section{Experimental apparatus}

Figure 5 shows that the experimental apparatus of 3D physical simulation for SAGD. The experimental apparatus mainly consists of three parts, including physical model section, injection section and data collection section.

The physical model section contains a 3D sand packing device (internal size is $40 \mathrm{~cm} \times 40 \mathrm{~cm} \times 40 \mathrm{~cm}$ ) that is resistant to high temperature and pressure as shown in Fig. 6 and a thermotank which can offset heat loss during the experiments. The steam injection section consists of an ISCO pump, a steam generator and a preheating device as shown in Fig. 7. The ISCO pump can control the flow rate into the steam generator and realize an accurate constant flow rate. The high quality and temperature steam can be generated by steam generator. Meanwhile the injection line 


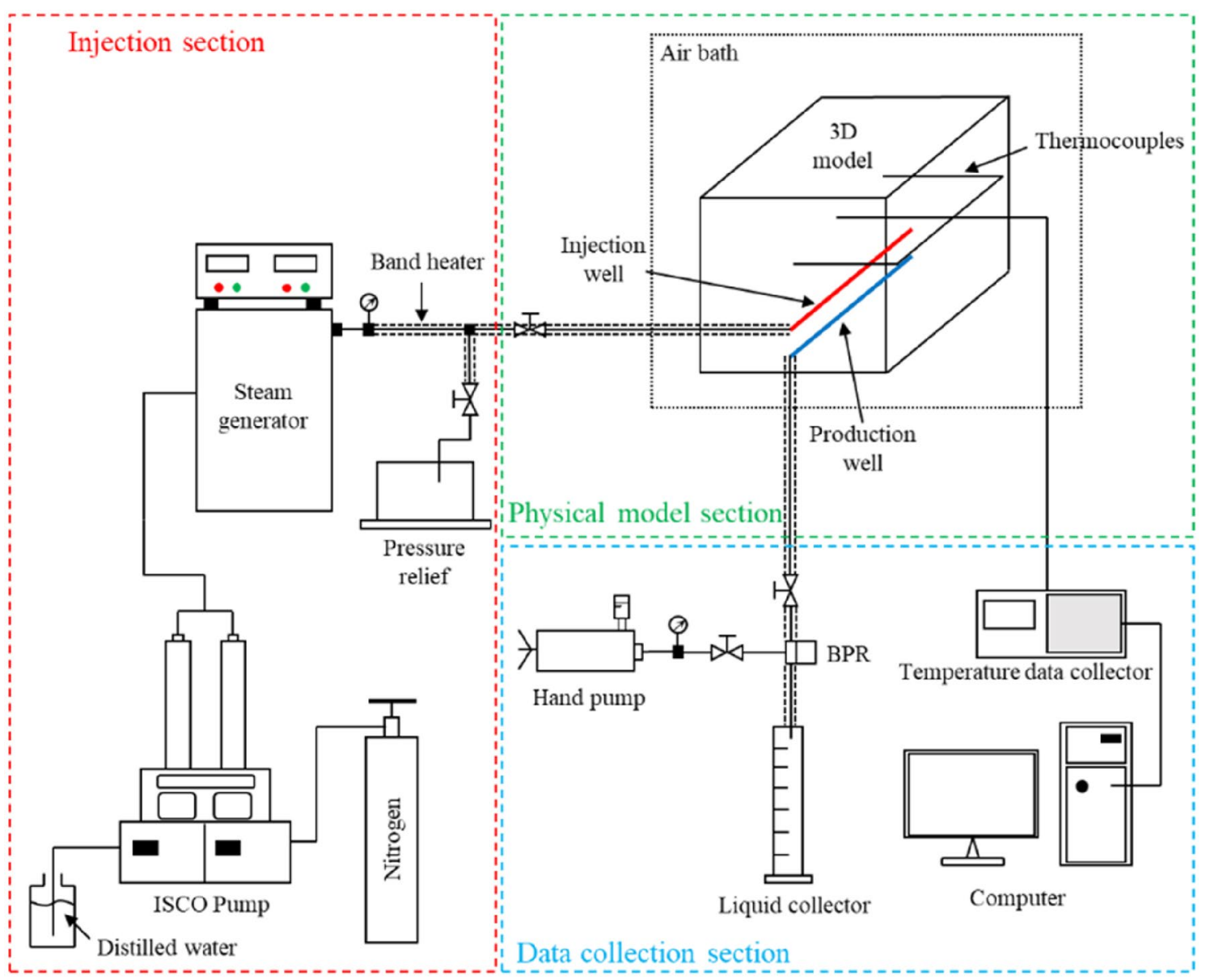

Fig. 5 Schematic diagram of experiment (Zhang et al., 2020)

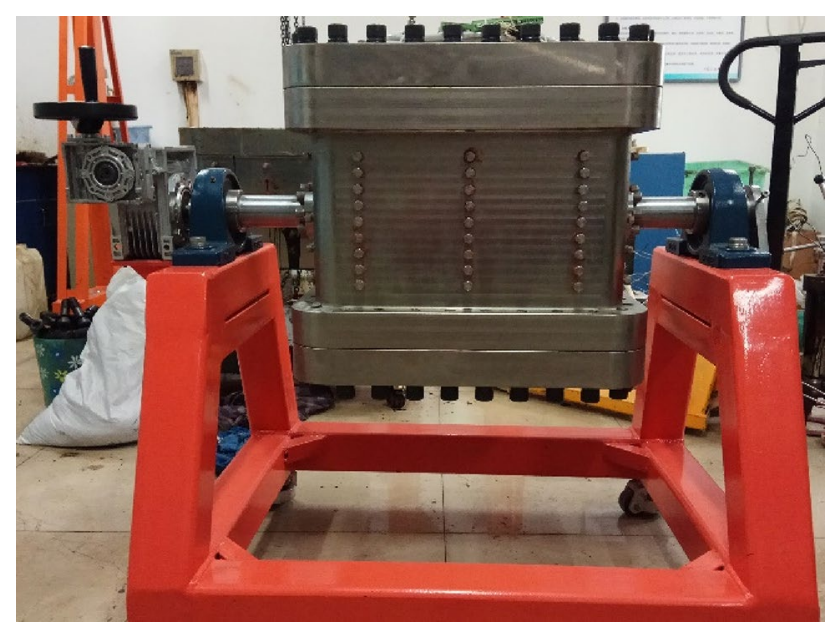

Fig. 6 Three-dimensional sand packing model

was wrapped with band heater for offsetting the heat loss. The data collection section includes temperature detector which can measure the temperature changes inside the model and back pressure regulator (BPR) which can

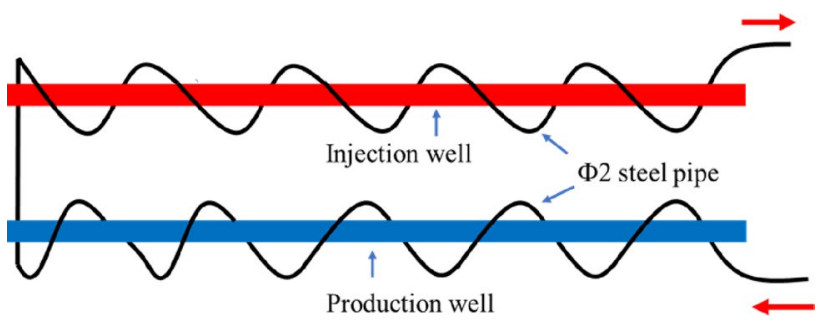

Fig. 7 Preheating device (Zhang et al., 2021)

control the total fluid production. The temperature distribution in real time can be measured by temperature detector and the data was collected and saved in the computer.

\section{Simulation procedures}

The procedures of experiment are described in detail as follow (Zhang et al., 2021): 
(1) Before the formal experiment, the experimental apparatuses were checked to ensure operate properly during the experiment.

(2) The sands were mixing with oil and water sufficiently in the thermotank, and the volume ratio of oil to water were as similar as the actual reservoir. Then, the injector and producer were placed in the bottom of model and twined with stainless pipeline, as shown in Fig. 7. And, temperature detectors were fixed in planned locations, as shown in Fig. 8.

(3) Before filling the model, the leakage test was conducted to the three-dimensional physical model. High pressure nitrogen was injected into physical model to increase the pressure to $5 \mathrm{MPa}$ and maintain the pressure for $12 \mathrm{~h}$.

(4) The under-burden, oil sands, breccia layer, oil sands and overburden were filled into the sand pack, respectively. To simulate low permeability zone in breccia layer, the cement was used to simulate the breccia. After sealing the model, heated oil was injected for filling the gap caused by model packing. This process was stopped until the model pressure increases to $2 \mathrm{MPa}$.

(5) Subsequently, preheating phase was started, steam would be injected continuously into the warped stainless pipe until temperature between injector and producer reached $90^{\circ} \mathrm{C}$

(6) During the SAGD process, steam was injected into the upper horizontal well and the heated oil drainage into the producer along the steam chamber. Finally, hot fluid flow through the BPR to the fluid collector. The collectors were marked and kept in the thermotank at 85 centigrade for separating water and oil.

\section{Results and discussion}

\section{Breccia layer effects on steam chamber expansion}

The comparison of temperature profile at different time between the two designed experiments as shown in Fig. 9. Figure 9A illustrates the evolution of steam chamber for traditional SAGD process. The steam chamber development can be obviously divided into three phases: rising, lateral spreading and confinement. Whereas the expansion speed of steam chamber is affected when the breccia layer exists, as shown in Fig. 9B. The rising steam is impeded and heat starts to spread laterally during the early SAGD process because the breccia interlayer blocks the path that steam rises and oil drains. Then, steam goes through the breccia layer and the steam chamber rises rapidly, which causes the heated area like a hexagonal shape (Fig. 9Ba). After $200 \mathrm{~min}$, the steam chamber reaches to the over-burden and expands laterally (Fig. 9Bc). But, the volume of steam chamber is obviously smaller than that of traditional SAGD (Fig. 9Ac). With following steam injection, the steam chamber spreads apparently along the horizontal direction. Due to the oil drainage velocity in breccia layer area is slow, the heated oil flows to producer will take more time. Therefore, much heated oil stuck in breccia interlayer area, which causes a thinner profile of chamber as shown in Fig. 9Bd. After $600 \mathrm{~min}$, the temperature of breccia interlayer area is increased to nearly $130^{\circ} \mathrm{C}$, which means the oil is heated well (Fig. 9Be). The steam chamber begins to expand downward and the steam chamber area is increased. However, Fig. 9Bf shows that the steam chamber area is much smaller than that of the formal SAGD at the end of experiment. Figure 10 shows the distribution of residual oil after the experiment. The steam chamber can only reach to the near injector area as shown in Fig. 10a, and most of the residual oil is concentrated in the breccia interlayer area (Fig. 10b) and the bottom of the model (Fig. 10c).

\section{Breccia interlayer effects on production performance}

Figure 11 illustrates the relationship of oil rate and water cut with time for the two experiments. As shown in Fig. 11a, the production performance can be divided into three stages, corresponding to the rising phase, lateral spreading phase and confinement phase, respectively. The oil rate and water cut increase sharply and then keep stable. Finally, the oil rate reduces and water cut increases gradually. Although the three production stages are still suitable for the experiment 2 , the production characteristics are different between the two experiments. The Fig. 11b shows the detailed production performance.

(1) Steam chamber rising: the oil rate and water cut increase rapidly with steam chamber rising.

(2) Steam chamber lateral spreading: During this stage, the temperature in the breccia interlayer area is increasing which causes the oil drainage resistance decreases in this area.. The oil rate increases and water cut decreases gradually. But, the time reaching to peak oil rate is obviously extended.

(3) Steam chamber going downwards: The oil in the breccia interlayer area is fully heated, and the oil drainage resistance is decreased obviously. The oil rate increases at the beginning of this stage and then decreases rapidly because the oil drainage height decreases.

Figure 12a shows the comparison of the instantaneous steam oil ratio between experiment 1 and experiment 2 . It can be seen that, when the formation has no breccia interlayer, it has a stable instantaneous steam oil ratio (iSOR) in the rising and lateral spreading stage. Whereas the iSOR of experiment 2 increases sharply at the beginning of SAGD process. This is because the breccia interlayer hinders the steam chamber rise and the heat efficiency of the injected steam is low. When the steam chamber reaches to the 


\begin{tabular}{|c|c|c|c|c|c|}
\hline \multirow{2}{*}{ (1) } & - & . & - & • & . \\
\hline & 1 & 11 & 21 & 31 & 41 \\
\hline \multirow{2}{*}{ (2) } & - & • & - & . & . \\
\hline & 2 & 12 & 22 & 32 & 42 \\
\hline \multirow{2}{*}{ (3) } & - & - & $\Delta$ & - & . \\
\hline & 3 & 13 & & 33 & 43 \\
\hline \multirow[t]{2}{*}{ (4) } & ; & $\therefore$ & , & $\dot{ }$ & - \\
\hline & 4 & 14 & 24 & 34 & 44 \\
\hline
\end{tabular}

(a) Distribution of thermocouples in vertical plane

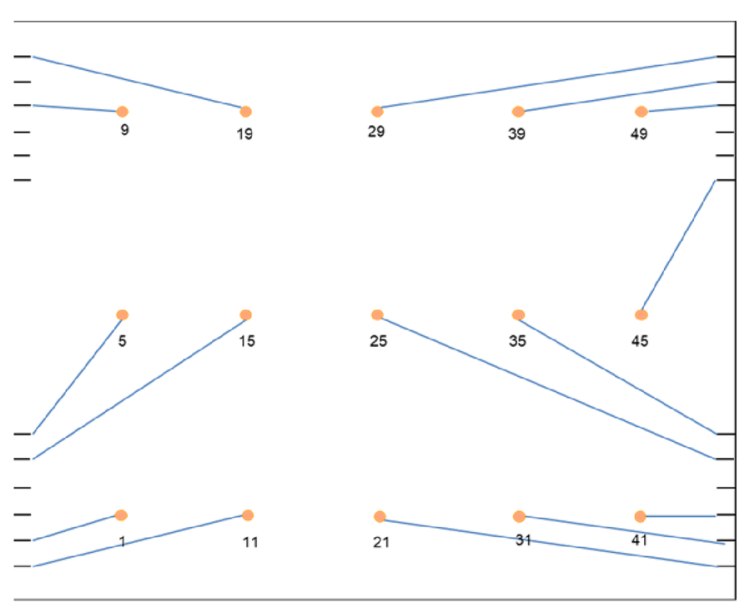

(1)

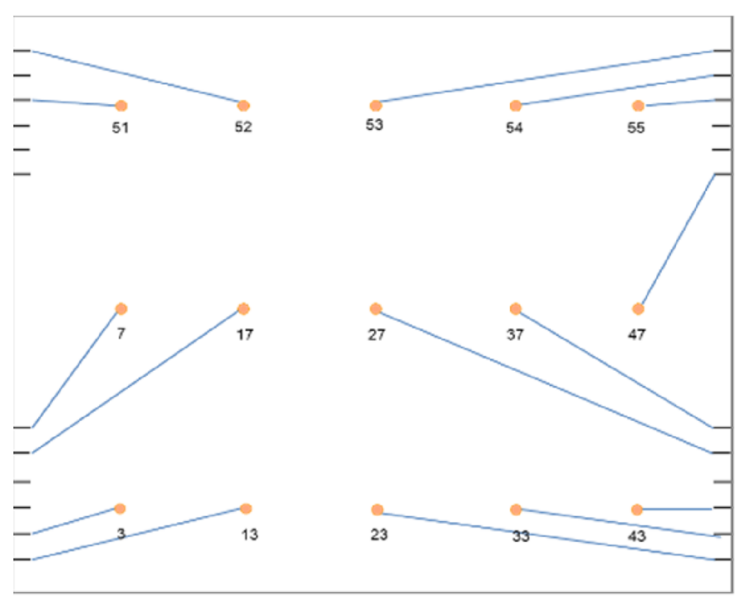

(3)

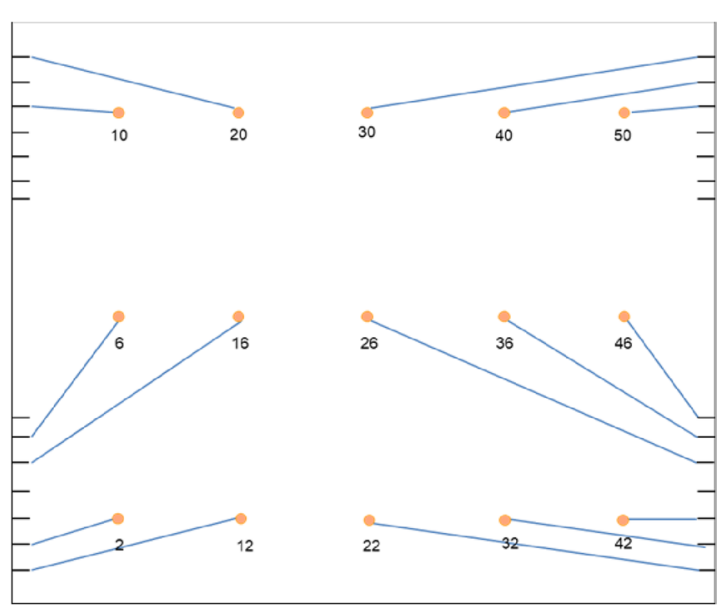

(2)

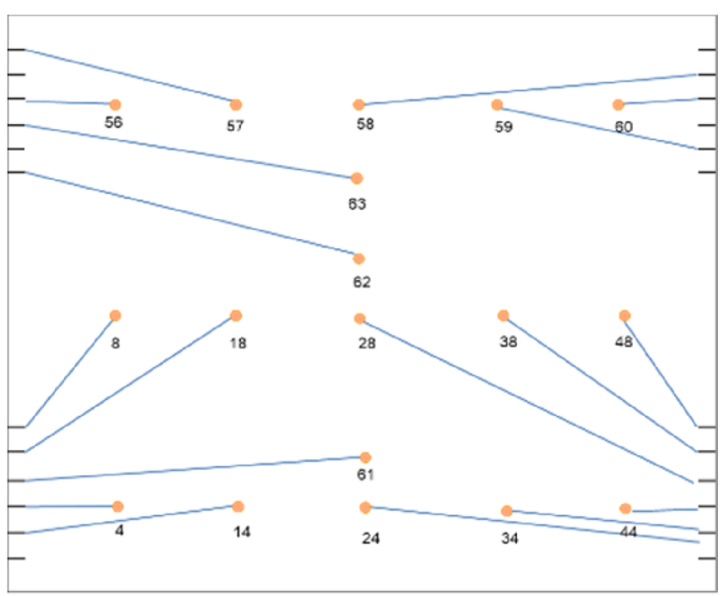

(4)

(b) Distribution of thermocouples in different horizontal planes

Fig. 8 Schematic diagram of the distribution of thermocouples 
Fig. 9 Temperature profile of the two experiments at different times. A Temperature profile of experiment 1 . B Temperature profile of experiment 2

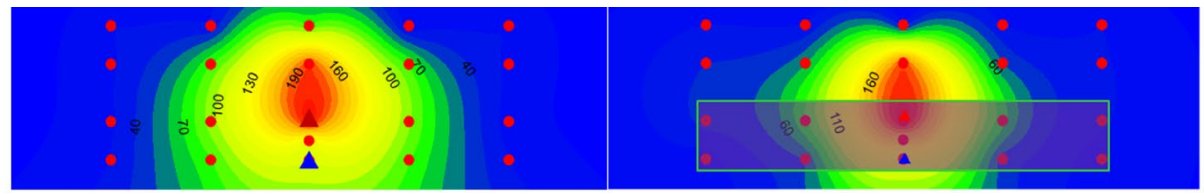

$\mathrm{A}(\mathrm{a}) \quad \mathrm{B} 0 \mathrm{~min} \quad \mathrm{~B}(\mathrm{a})$

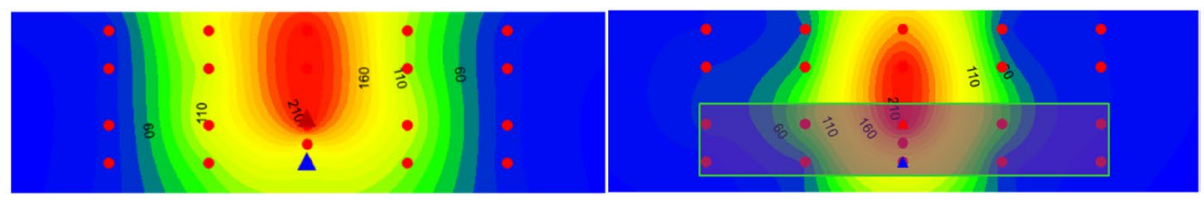

$\mathrm{A}(\mathrm{b})$

$100 \mathrm{~min}$

$\mathrm{B}(\mathrm{b})$

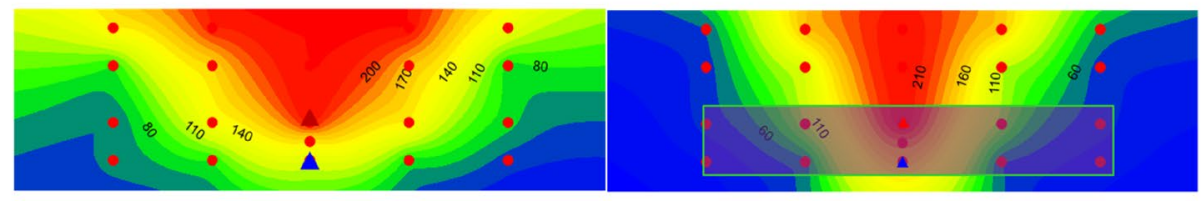

$\mathrm{A}(\mathrm{c})$

$200 \mathrm{~min}$

$\mathrm{B}(\mathrm{c})$

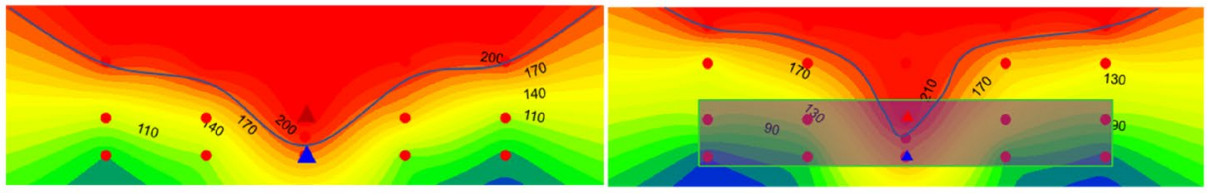

$\mathrm{A}(\mathrm{d}) \quad 400 \mathrm{~min} \quad \mathrm{~B}(\mathrm{~d})$
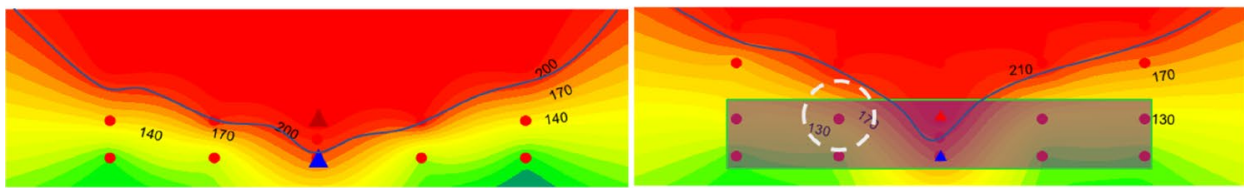

$\mathrm{A}(\mathrm{e}) \quad 600 \mathrm{~min} \quad \mathrm{~B}(\mathrm{e})$
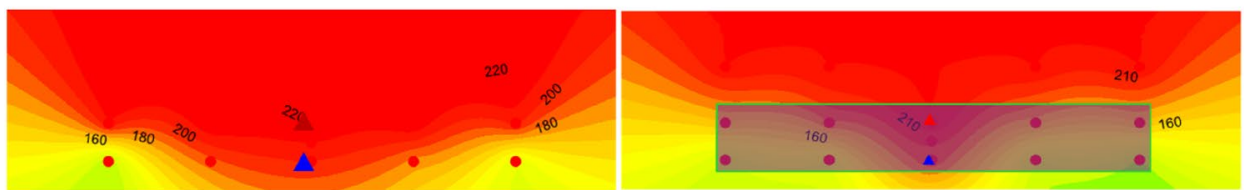

$\mathrm{A}(\mathrm{f}) \quad 800 \mathrm{~min} \quad \mathrm{~B}(\mathrm{f})$

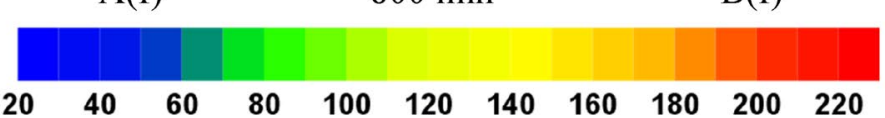

over-burden, the iSOR keeps stable. With the steam chamber expanding, the breccia interlayer area is fully heated and the flow resistance in this area is obviously decreased, which causes the steam oil ratio decreases gradually. After the chamber reaches to the lateral boundary of the model, the steam oil ratio increases rapidly.

Figure $12 \mathrm{~b}$ shows the oil recovery performance for the two experiments. It shows the experiment 1 and experiment 2 have different varying tendency. Experiment 1 increases quickly in the early SAGD process and then the increasing trend decreases gradually, whereas experiment 2 has a slow increasing trend in the early SAGD process, and then a quick increasing trend. However, there is still much unrecoverable oil in the model compared with experiment 1 because the gravity cannot provide sufficient driving force to drain the oil through the breccia interlayer area, as shown in Fig. 10. 


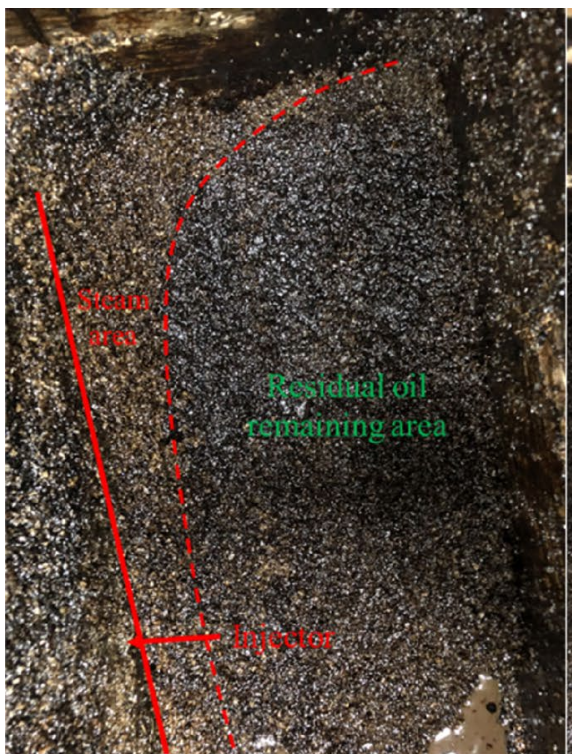

(a)

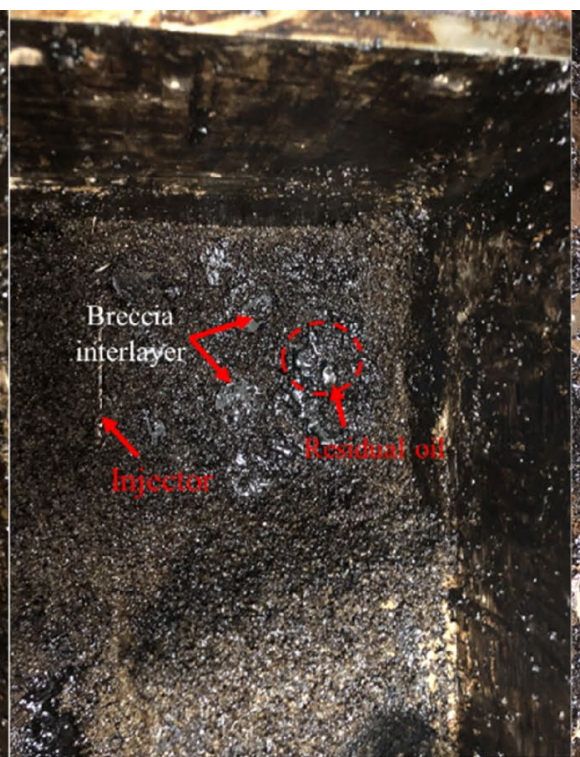

(b)

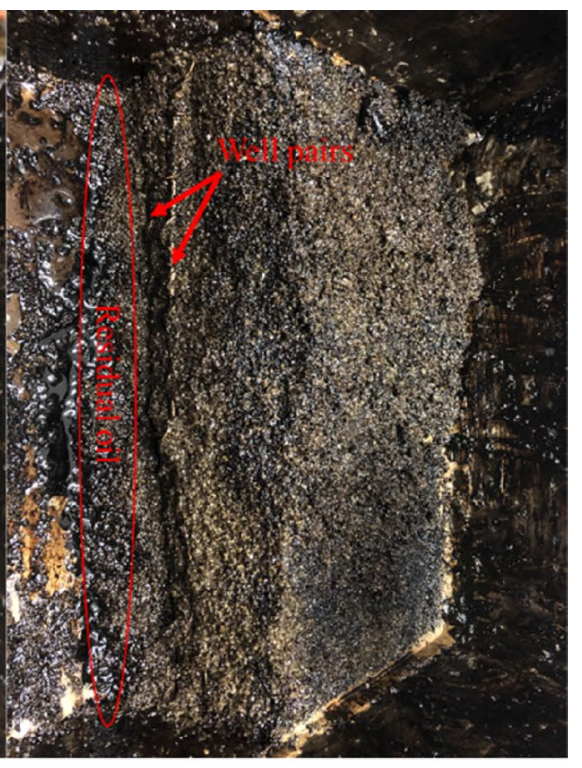

(c)

Fig. 10 Area of residual oil. a Residual oil distribution in the horizontal plane above the injector. b Residual oil distribution in breccia layer area. c Residual oil distribution in the bottom of the model

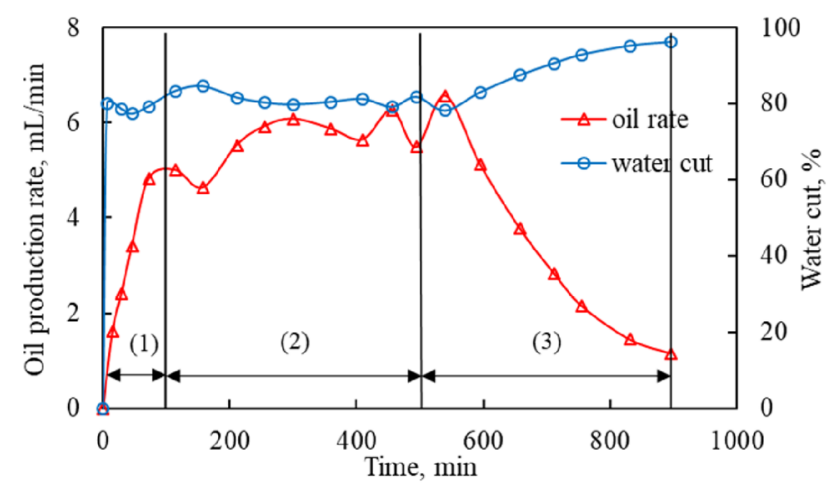

(a) Experiment 1

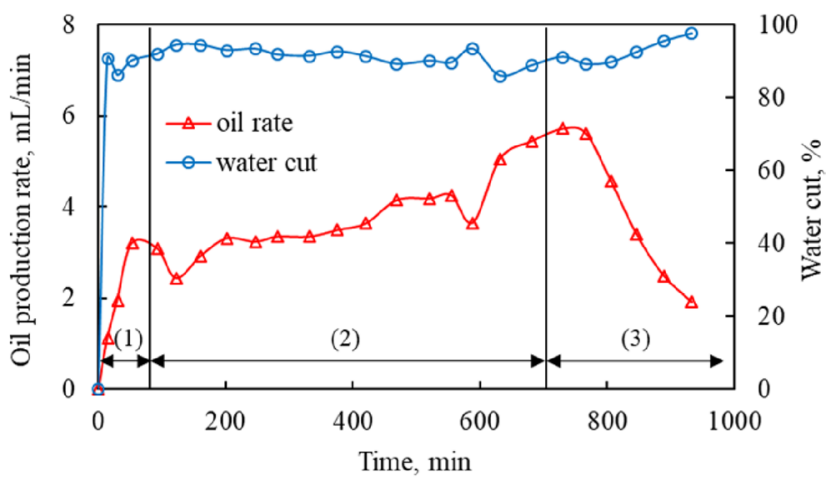

(b) Experiment 2

Fig. 11 Relationship between oil rate/water cut and time for the two experiments

\section{Numerical simulation}

\section{Numerical model}

In this work, the CMG-STARS was used as numerical simulator. In order to simulate the real condition of experiment, the numerical model was built based on the laboratory scale experiment as shown in Fig. 13. The grid number of the model in $i, j$ and $k$ direction were $25 \times 25 \times 29$, respectively. The grid block size of reservoir part was $1.5 \mathrm{~cm} \times 1.5 \mathrm{~cm} \times 0.5 \mathrm{~cm}$. The key parameters used in this model were listed in Table 3. Figure 14 shows the relationship of oil and water relative permeability. To study the influence of breccia layer on SAGD performance, two breccia layer patterns were designed, as shown in Fig. 15. Pattern A is that breccia layer area covers the injector and producer. The breccia layer area covers the producer only in Pattern B. As shown in Fig. 15, the dark blue area represents breccia and the light blue area represents oil drainage path between the breccia. In reality, the permeability of oil drainage path is lower than other part of reservoir. Therefore, different schemes were designed as shown in Table. 4. 


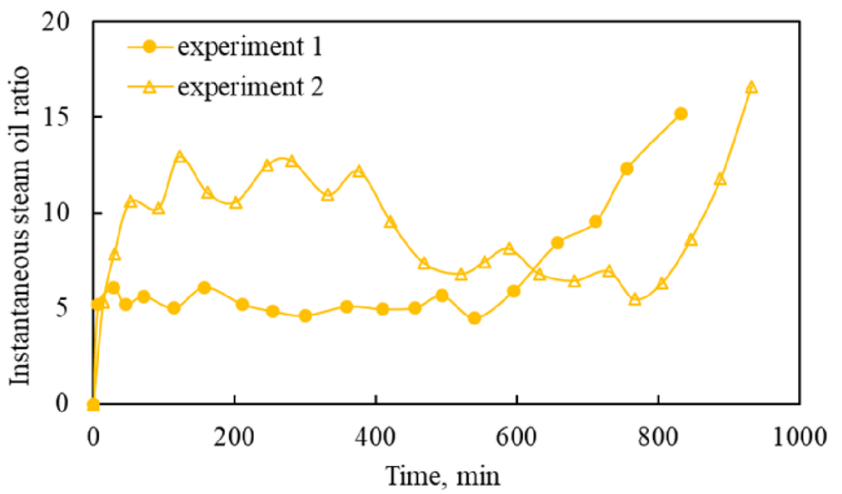

(a) Instantaneous steam oil ratio curves

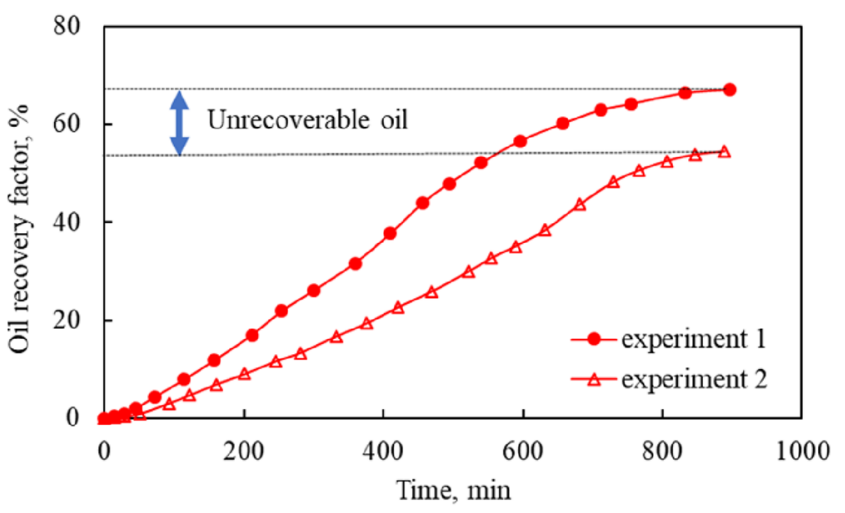

(b) Oil recovery factor curves

Fig. 12 Comparison of instantaneous steam oil ratio/oil recovery for the two experiments
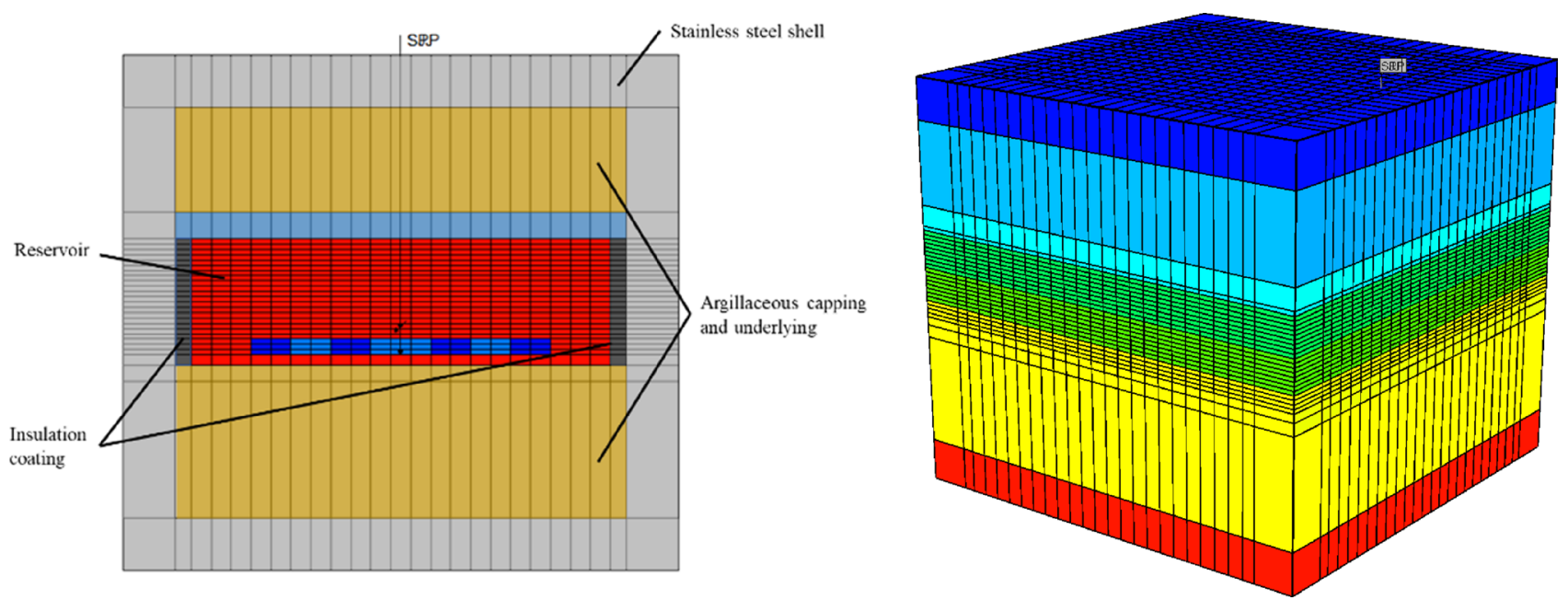

Fig. 13 Schematic of the laboratory scale numerical stimulation model

Table 3 Parameters of the numerical simulation model

\begin{tabular}{lll}
\hline Parameters & Value & Unit \\
\hline Reservoir thickness & 12 & $\mathrm{~cm}$ \\
Reservoir temperature & 20 & ${ }^{\circ} \mathrm{C}$ \\
Reservoir pressure & 2.2 & $\mathrm{MPa}$ \\
Permeability & 40 & $\mu \mathrm{m}^{2}$ \\
Porosity & 0.33 & - \\
Initial oil saturation & 0.86 & - \\
Permeability of breccia interlayer & 200 & $\mathrm{mD}$ \\
Rock thermal conductivity & 1.4 & $\mathrm{~J} /\left(\mathrm{cm} \cdot \mathrm{min} \cdot{ }^{\circ} \mathrm{C}\right)$ \\
Cement thermal conductivity & 0.682 & $\mathrm{~J} /\left(\mathrm{cm} \cdot \mathrm{min} \cdot{ }^{\circ} \mathrm{C}\right)$ \\
Stainless steel thermal conductivity & 11.8 & $\mathrm{~J} /\left(\mathrm{cm} \cdot \mathrm{min} \cdot{ }^{\circ} \mathrm{C}\right)$ \\
Water thermal conductivity & 0.37 & $\mathrm{~J} /\left(\mathrm{cm} \cdot \mathrm{min} \cdot{ }^{\circ} \mathrm{C}\right)$ \\
Oil thermal conductivity & 0.18 & $\mathrm{~J} /\left(\mathrm{cm} \cdot \mathrm{min} \cdot{ }^{\circ} \mathrm{C}\right)$ \\
Overburden thermal conductivity & 0.42 & $\mathrm{~J} /\left(\mathrm{cm} \cdot \mathrm{min} \cdot{ }^{\circ} \mathrm{C}\right)$ \\
\hline
\end{tabular}

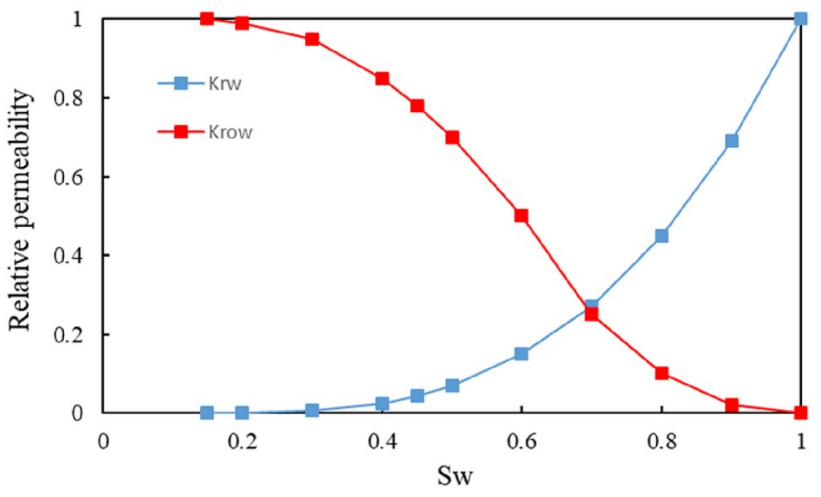

Fig. 14 Relative permeability curves 


\section{History matching}

Figure 16 shows the comparisons of the results of experiment and numerical simulation in the condition of Pattern A-1. Figure 16a illustrates the oil rate and water cut. And Fig. $16 \mathrm{~b}$ shows the cumulative oil production. It can be seen that the numerical simulation results can match the experimental results very well. Figure 17 shows the experimental and numerical simulation temperature distribution at different times. It can be seen that the steam chamber of numerical simulation at $800 \mathrm{~min}$ is larger than that of experiment because the heat loss in the actual experiment sideways is more than that in theoretical calculation. However, the temperature profile and production performance of experiment and numerical simulation matched well during the whole SAGD process. Therefore, the numerical model is reliable
Fig. 15 Schematic of the breccia layer patterns in numerical model
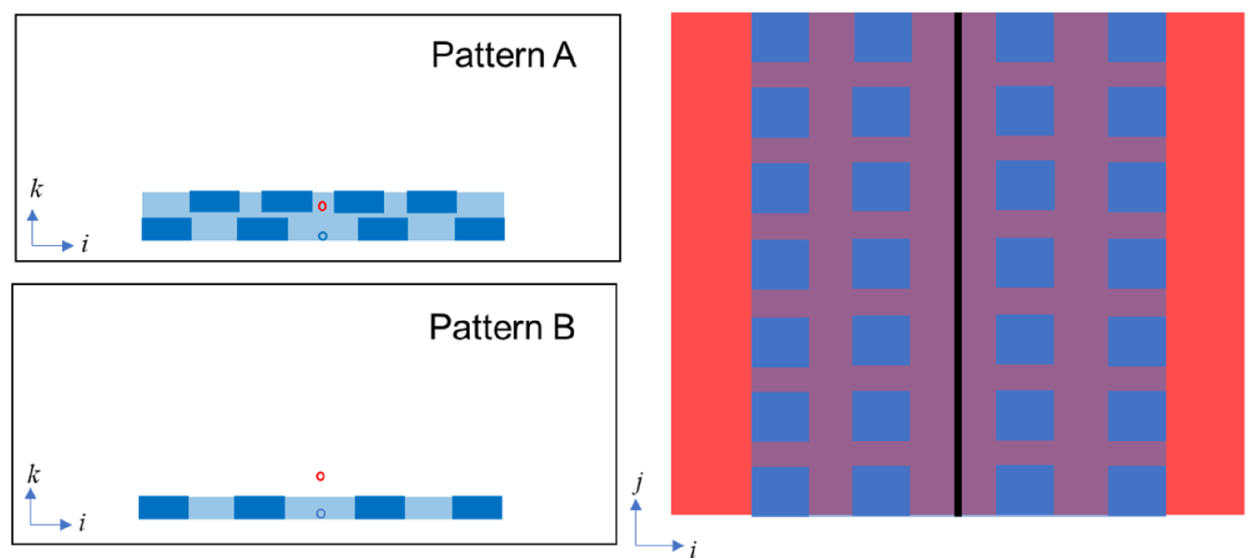

Table 4 Different schemes for numerical simulation

\begin{tabular}{llllll}
\hline Model & $\begin{array}{l}\text { Thickness of brec- } \\
\text { cia layer }(\mathrm{cm})\end{array}$ & $\begin{array}{l}\text { Permeability in brec- } \\
\text { cia layer area }\left(\mu \mathrm{m}^{2}\right)\end{array}$ & Model & $\begin{array}{l}\text { Thickness of brec- } \\
\text { cia layer }(\mathrm{cm})\end{array}$ & $\begin{array}{l}\text { Permeability in } \\
\text { breccia layer area } \\
\left(\mu \mathrm{m}^{2}\right)\end{array}$ \\
\hline A-1 & 3.5 & 40 & B-1 & 1.5 & 40 \\
A-2 & 3.5 & 30 & B-2 & 1.5 & 30 \\
A-3 & 3.5 & 20 & B-3 & 1.5 & 20 \\
A-4 & 3.5 & 10 & B-4 & 1.5 & 10 \\
A-5 & 3.5 & 8 & B-5 & 1.5 & 8 \\
A-6 & 3.5 & 5 & B-6 & 1.5 & 5 \\
\hline
\end{tabular}

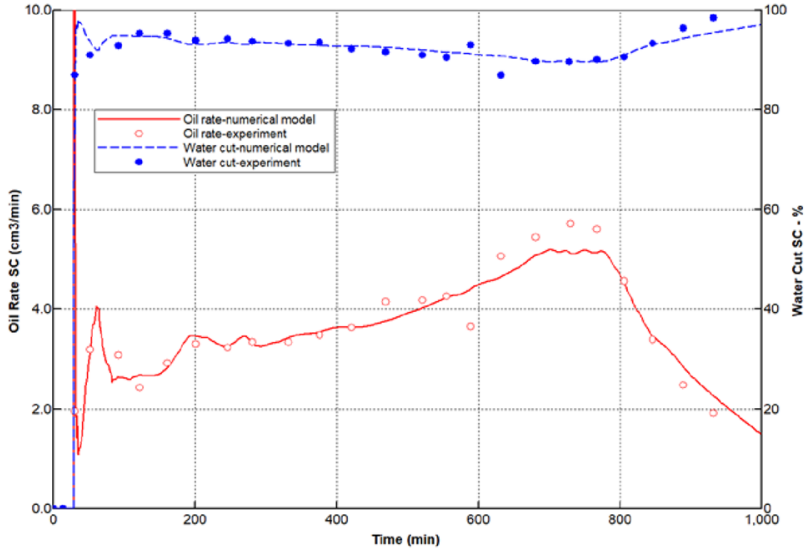

(a) Oil rate and water cut

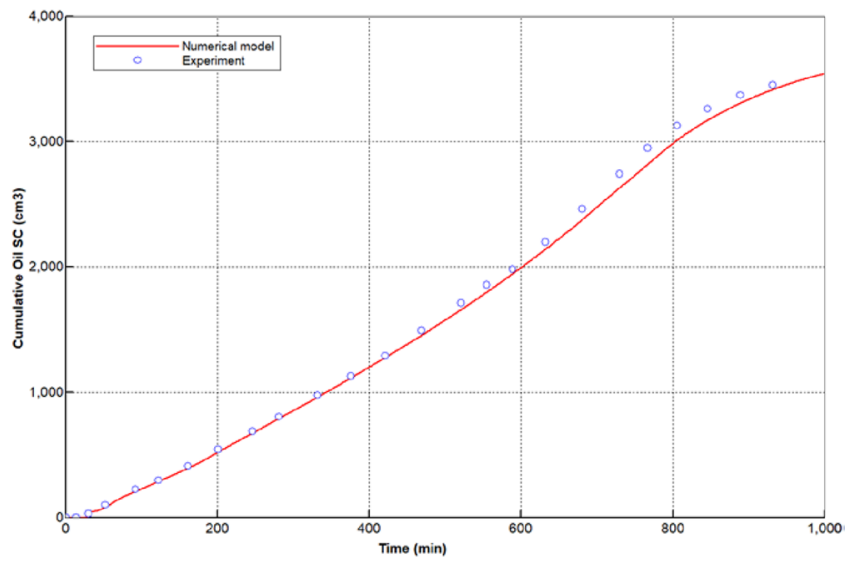

(b) Cumulative oil production

Fig. 16 History matching results 


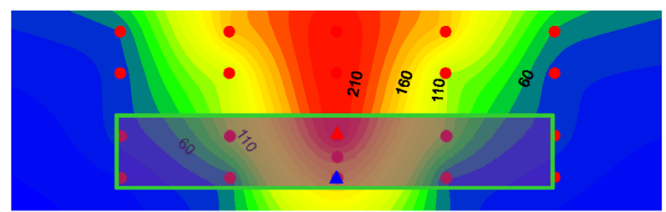

$200 \min$
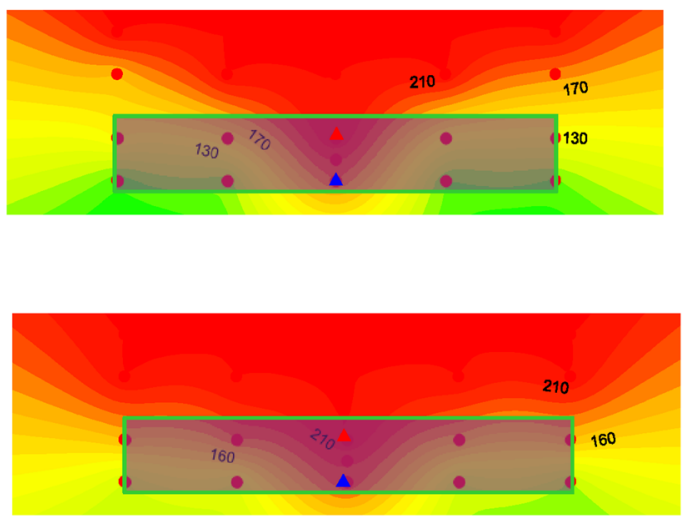

$800 \mathrm{~min}$

Experiment

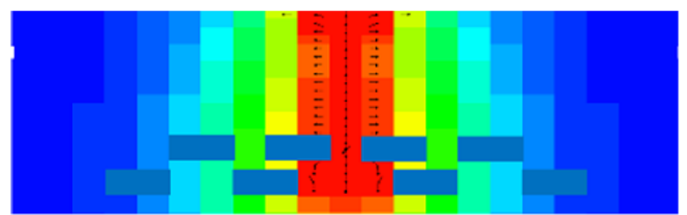

$200 \mathrm{~min}$

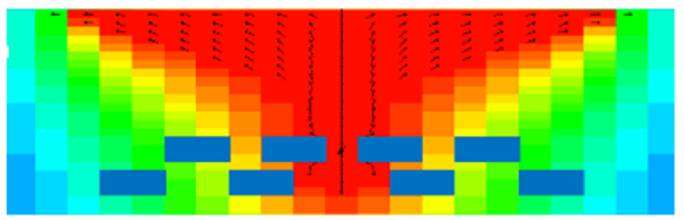

$600 \mathrm{~min}$

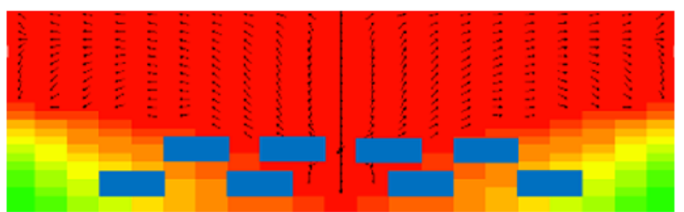

$800 \mathrm{~min}$

\section{Numerical model}

Fig. 17 Comparison of experimental and numerical simulated temperature profile

for predicting and optimizing the experimental results with different reservoir parameters.

\section{Effects of breccia layer thickness on SAGD performance}

Figure 18 shows the oil rate, oil recovery factor and iSOR curves for different models. It can be seen that the results of pattern B-1 are close to the results of traditional SAGD. But, the oil rate of pattern A-1 is much slower during the SAGD process and the iSOR is obviously larger. This indicates that a thicker breccia layer can impede oil drain to the producer, which causes the time of second peak of production increases. But, the thickness of breccia interlayer effects the oil rate during the SAGD process not the ultimate recovery as shown in Fig. 18b, if the production time is long enough.

The profile of oil saturation for different models, as shown in Fig. 19. It can be seen that the residual oil is mainly distributed in breccia interlayer area and both sides of model. The speed of steam chamber expansion is apparently lower, especially when the thickness of breccia interlayer is larger. This is because the breccia hinders oil flow from the steam chamber edge to the producer and the oil drainage path is extended, which causes a longer time for drainage.
Therefore, the thicker the thickness of breccia interlayer, the longer the oil drainage path and the lower the speed of steam chamber expansion were.

\section{Effects of breccia interlayer permeability on SAGD performance}

In this section, the permeability of breccia interlayer area effects on SAGD performance was studied. Different permeabilities of two patterns were designed in Table. 4.

Figure 20a shows the oil rate of each simulation case. It can be seen that the pattern A is more sensitive to permeability than the pattern B. In pattern A, the first and second peak of production increases with permeability, but the time of second peak of production is decreases with permeability. With the permeability decreases, the oil rate in a lower and stable level after steam chamber reaching to the top of model. However, the oil rates of different models in pattern $\mathrm{B}$ are close during the earlier stage and the influence of permeability on pattern B is obviously smaller. Furthermore, the differences of oil rate between the models enlarge with time. The lower the permeability in breccia interlayer area, the lower the oil rate was during the steam chamber spreading laterally.

Figure 20b shows the permeability effects on iSOR characteristics of different patterns. The lower the 


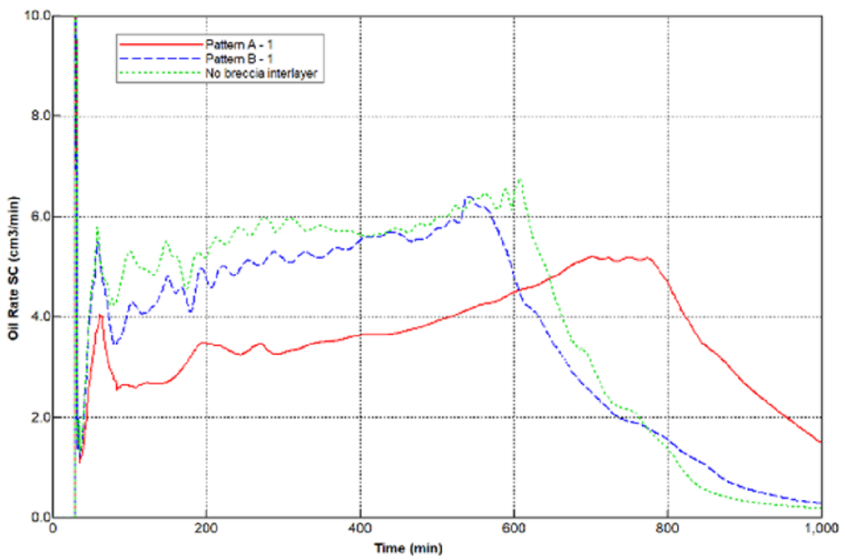

(a) Oil rate curves

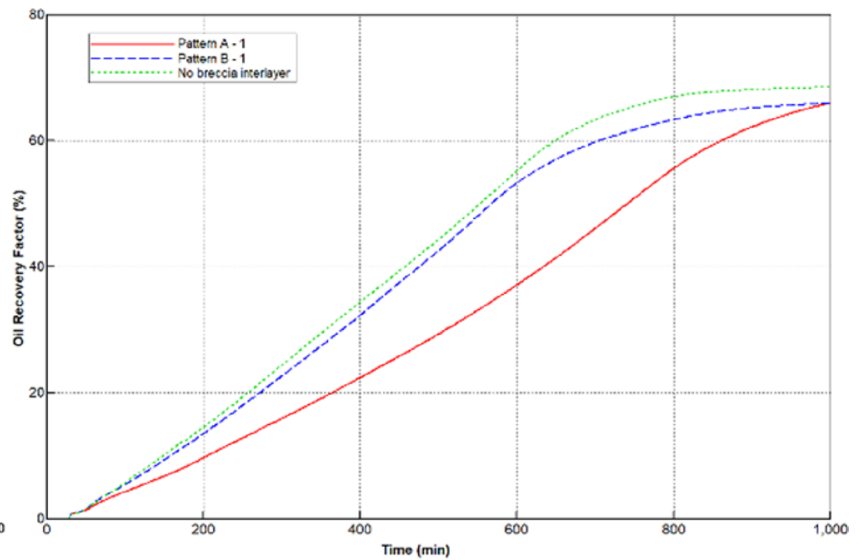

(b) Oil recovery factor curves

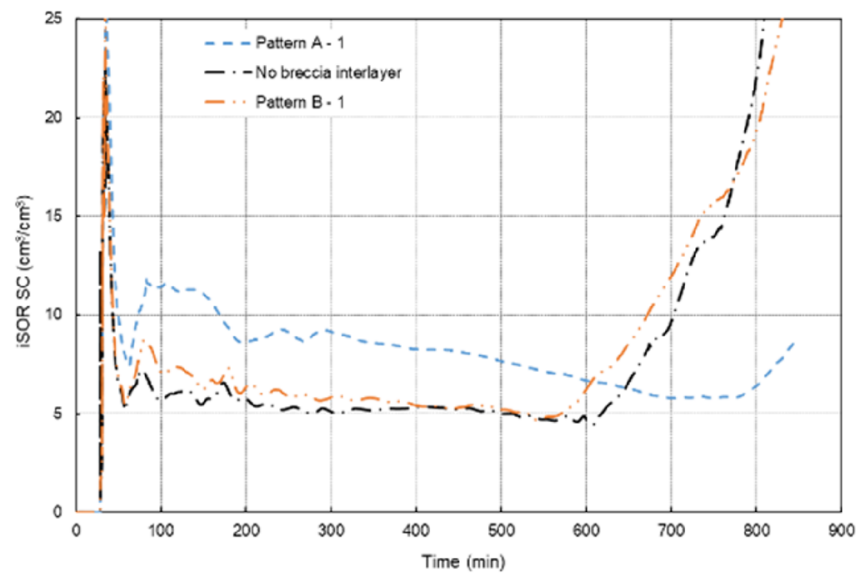

(c) Instantaneous steam oil ratio curves.

Fig. 18 Comparison of production performance curves for different models

A-1

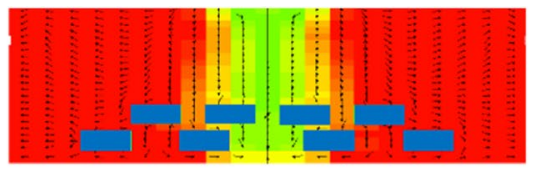

B-1
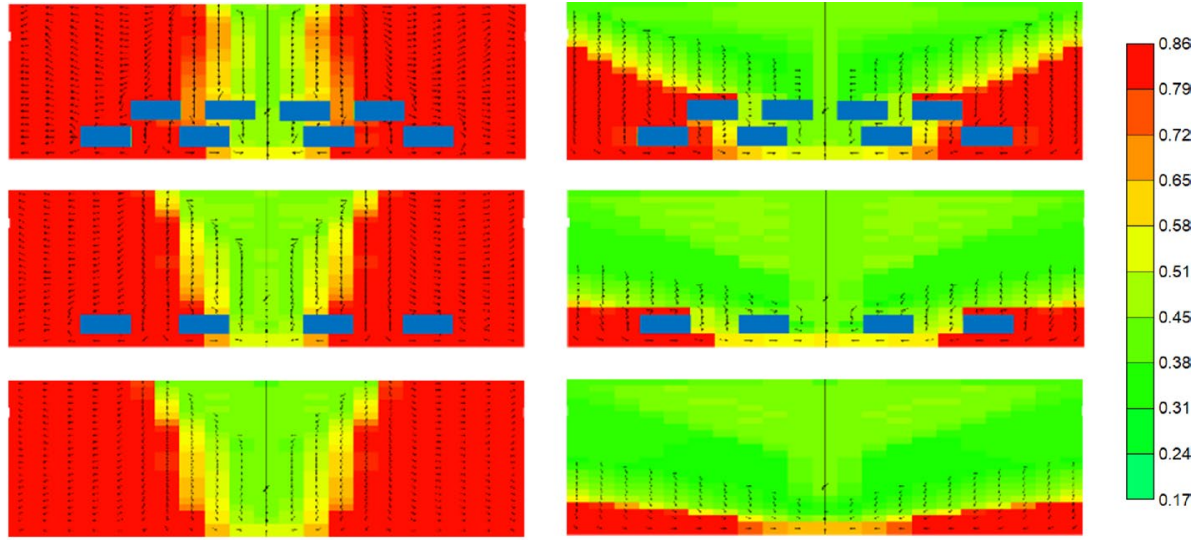

$600 \mathrm{~min}$

$$
600 \mathrm{~min}
$$

Fig. 19 Oil saturation profile of different patterns 

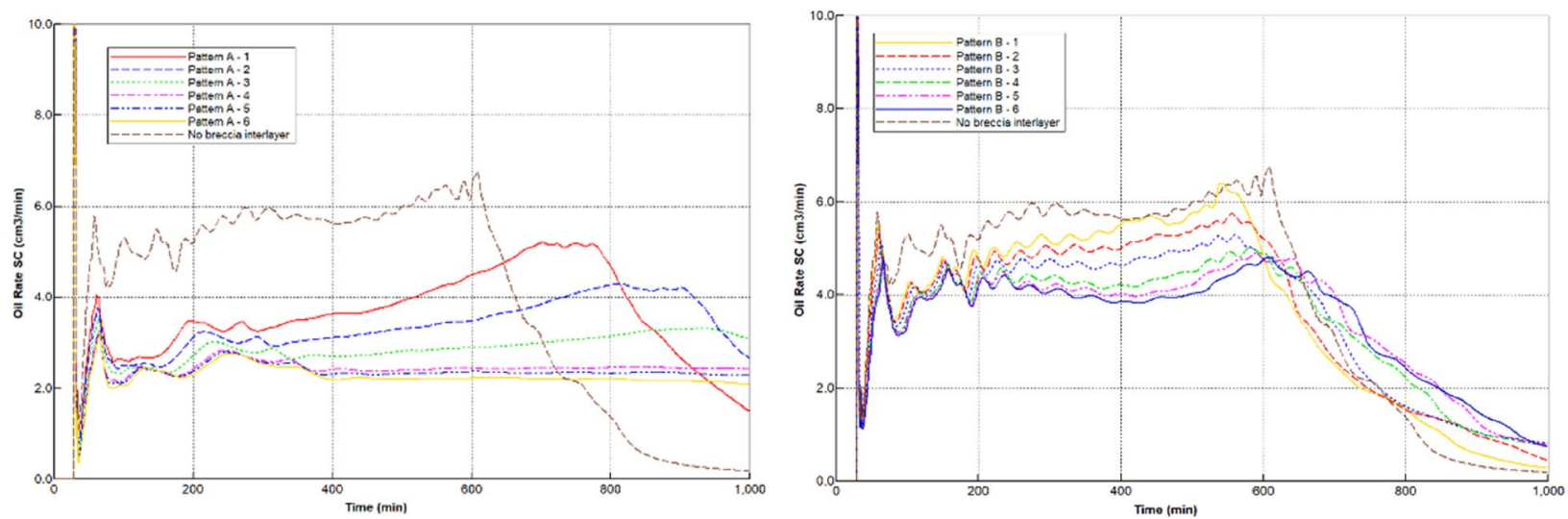

(a) Oil rate curves
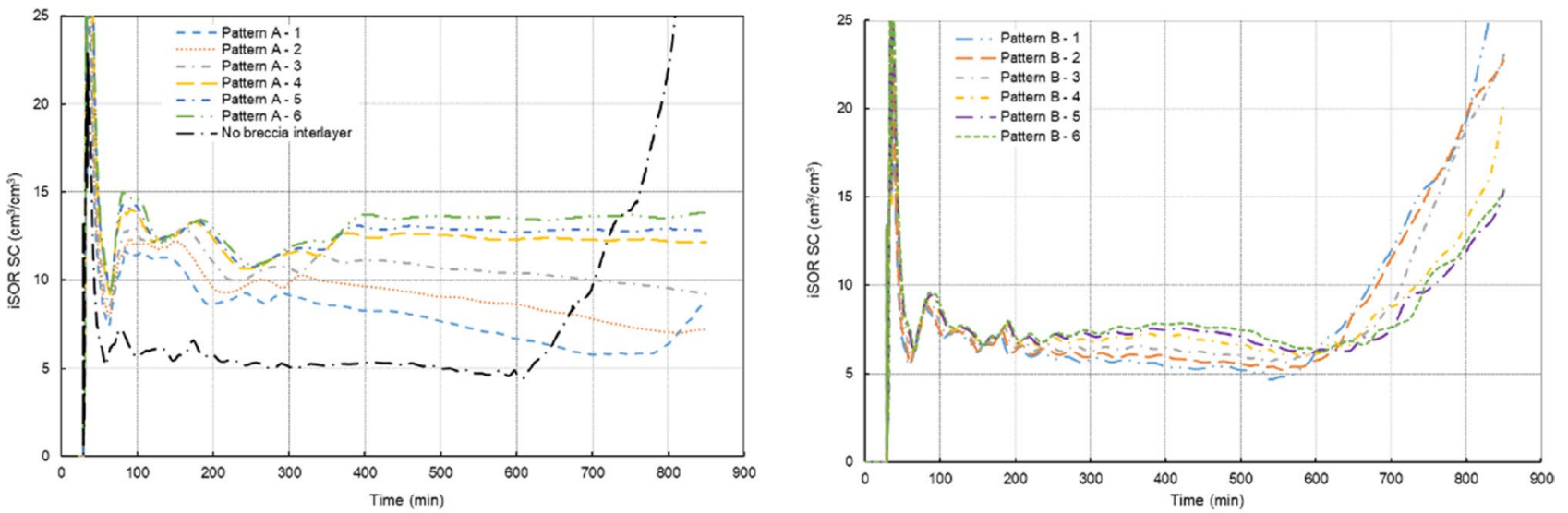

(b) Instantaneous steam oil ratio curves
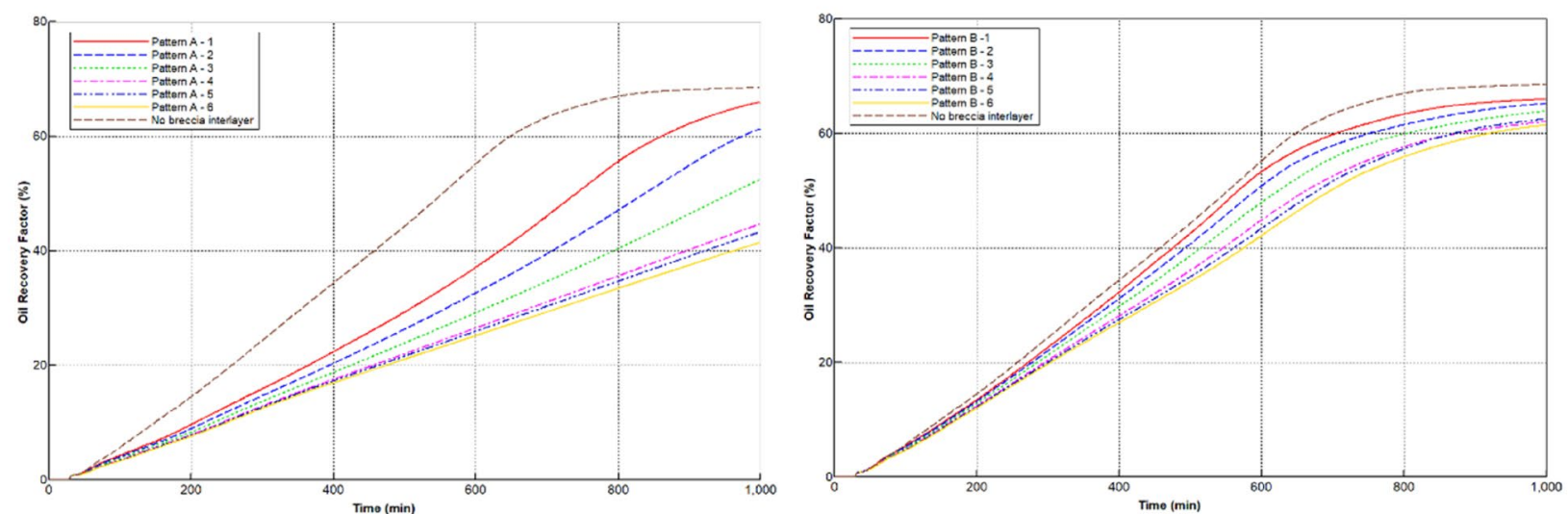

(c) Oil recovery factor curves.

Fig. 20 Comparison of production performance curves for different models 
permeability of pattern A, the higher the iSOR was. Whereas the permeability had less influence on iSOR of pattern B and the iSOR of pattern B was obviously lower. This indicates that the permeability in breccia interlayer area had a little effect on iSOR when the thickness of breccia interlayer was thinner.

Figure 20c shows permeability effects on oil recovery of different models. It can be seen that the performance of pattern A became worse with the permeability decreases. Besides, pattern A-4, A-5 and A-6 have a very low ultimate oil recovery, which indicates that when the permeability in breccia interlayer area is lower, the traditional SAGD technology is no longer suitable for developing this pattern of oil sands reservoirs. The influences of permeability on pattern B were not significant compared with that of pattern A. Therefore, the thicker the breccia interlayer area and the lower the permeability in breccia interlayer, the greater impact on the SAGD performance was.

Figure 21 shows the temperature profiles of pattern A-1, A-3 and A-6 at 200, 500 and 800 min, respectively. It can be seen that a lower permeability in breccia interlayer area hindered the steam chamber rising and the heated oil drainage during the entire SAGD process. In model A-1, the permeability in breccia interlayer area is equal to the other part of reservoir. The steam can quickly expand and heat the breccia interlayer area which causes the heated oil can easily bypass the breccia. In model A-3 and A-6, however, the speed of steam chamber expansion decreases rapidly as the decrease of permeability. When the steam chamber of model A-1 fully heat the breccia interlayer area, the steam chamber of model A- 6 has not reached to the lateral boundary of the model and much oil is still not recovered.

A-6
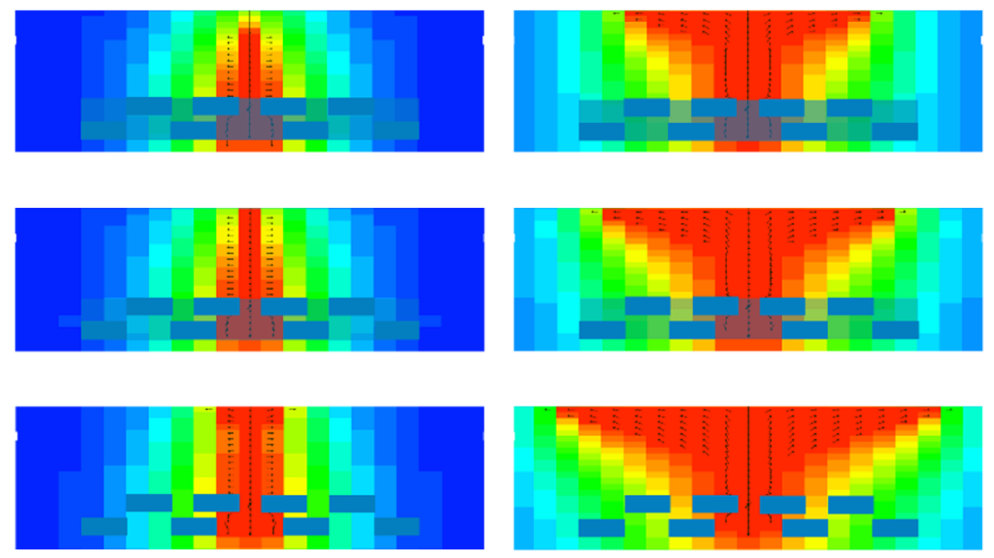

$200 \mathrm{~min}$

$500 \mathrm{~min}$
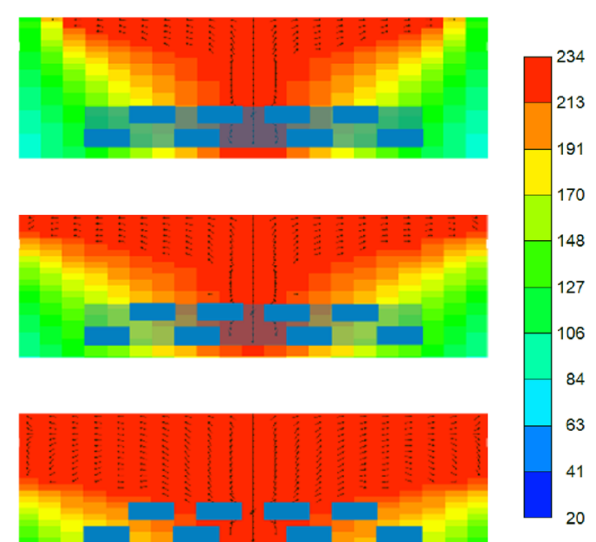

Fig. 21 Comparison of temperature profile for different models of pattern A
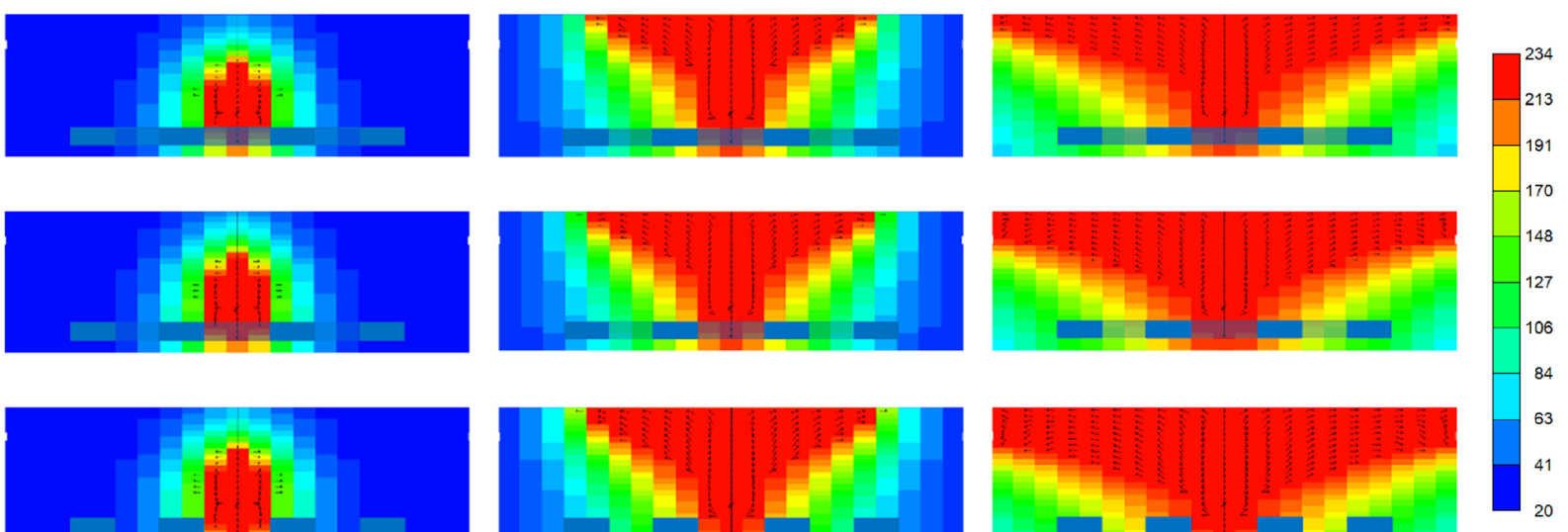

B-3
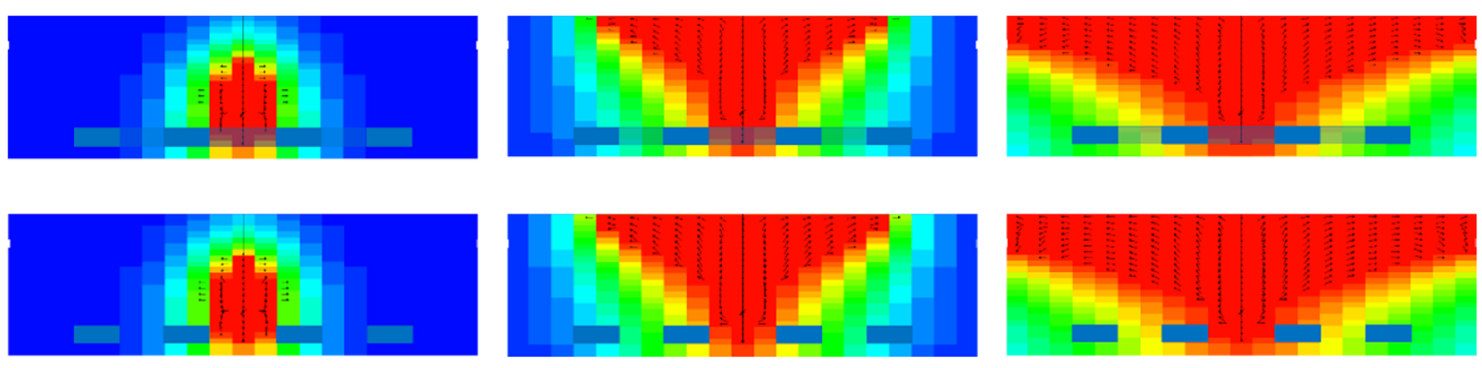

$300 \mathrm{~min}$

$500 \mathrm{~min}$

Fig. 22 Comparison of temperature profile for different models of pattern B 
Figure 22 indicates the temperature profiles for different models at 100, 300 and $500 \mathrm{~min}$, respectively. The comparison of the three models indicates that the permeability has little impact on the steam chamber expansion during the rising and early lateral spreading phase. However, the resistance effect of low permeability on heated oil through the breccia interlayer area was increased gradually due to the oil drainage area increased with the steam chamber spreads laterally. And the lower permeability was, the development of steam chamber was more lagged.

\section{Conclusion}

The main conclusions were drawn as following:

(1) The breccia interlayer can greatly influence the steam chamber expansion and production characteristics, results show that the profile of steam chamber is obviously thinner near the production well area and the time to reach peak oil rate is obviously extended.

(2) The existence of breccia interlayer impedes the heated oil drainage to the producer, and large quantities of oil still remain in breccia layer area at the end of SAGD process, which causes a $15.8 \%$ reduction in oil recovery.

(3) The thickness of breccia layer has a great impact on production performance, especially when the breccia layer covers the injector and producer. But it has little effect on ultimate oil recovery if the production time is long enough.

(4) The influence of permeability in breccia layer area on SAGD performance depends on the thickness of breccia layer. A lower permeability in breccia layer area causes a serious adverse effect on oil recovery if the interlayer thickness is thicker. However, the permeability in breccia layer area effects on SAGD performance is limited, when the breccia layer is thinner.

Funding The financial Supported by the National Natural Science Foundation of China (No.52074347).

\section{Declarations}

Conflict of interest The author declared that there is no conflict of interest.

Open Access This article is licensed under a Creative Commons Attribution 4.0 International License, which permits use, sharing, adaptation, distribution and reproduction in any medium or format, as long as you give appropriate credit to the original author(s) and the source, provide a link to the Creative Commons licence, and indicate if changes were made. The images or other third party material in this article are included in the article's Creative Commons licence, unless indicated otherwise in a credit line to the material. If material is not included in the article's Creative Commons licence and your intended use is not permitted by statutory regulation or exceeds the permitted use, you will need to obtain permission directly from the copyright holder. To view a copy of this licence, visit http://creativecommons.org/licenses/by/4.0/.

\section{References}

Baghernezhad D, Siavashi M (2019) Optimal scenario design of steamassisted gravity drainage to enhance oil recovery with temperature and rate control. Energy 166:610-623

Butler RM (1985) A new approach to the modeling of steam assisted gravity drainage. J Can Pet Technol 24(03):42-52

Butler RM, Stephens DJ (1981) The gravity drainage of steamheated heavy oil to parallel horizontal wells. J Can Pet Technol 20(2):36-36

Chen, Q., Gerristen, M. G., and Kovscek, A. R. 2007. Effects of reservoirs heterogeneities on the steam-assisted gravity drainage process. Paper SPE 109873, presented at the 2007 SPE Annual Technical Conference and Exhibition, Anaheim, California, U.S.A., 11-14 November.

Dang CTQ, Chen Z, Nguyen TBN, Bae W, Mai CL (2013) Numerical Simulation of SAGD Recovery Process in Presence of Shale Barriers. Thief Zones, and Fracture System, Petroleum Science and Technology 31(14):1454-1470

Doan Q, Farouq AS, M., George Albert E. (1992) Scaling criteria and model experiments for horizontal wells. J Can Pet Technol 31(9):57-65

Dong X, Liu H, Chen Z, Wu K, Lu N, Zhang Q (2019) Enhanced oil recovery techniques for heavy oil and oilsands reservoirs after steam injection. Appl Energy 239:1190-2121

Gao Y, Guo E, Luo J, Jiang. Y, Wang H, Wei Y (2016). Case Study on a New Approach for Exploiting Heavy Oil Reservoirs with Shale Barriers. In SPE EOR Conference at Oil and Gas West Asia. Society of Petroleum Engineers.

Gates ID, Chakrabarty N (2006) Optimization of steam assisted gravity drainage in McMurray reservoir. J Can Pet Technol 45(5):54-62

Huang S, Yang L, Xia Y, Du M, Yang Y (2019) An experimental and numerical study of a steam chamber and production characteristics of SAGD considering multiple barrier layers. J Petrol Sci Eng 180:716-726

Joshi S D. A laboratory study of thermal oil recovery using horizontal wells. In: Paper SPE-14916-MS presented at SPE Enhanced Oil Recovery Symposium, Tulsa, Oklahoma, 20-23 April 1986.

Kim M, Shin H (2018) Development and application of proxy models for predicting the shale barrier size using reservoir parameters and SAGD production data. J Petrol Sci Eng 170:331-344

Kim M, Shin H (2020) Machine learning-based prediction of the shale barrier size and spatial location using key features of SAGD production curves. J Petrol Sci Eng 191:107205

Kimber KD, Farouq AS, M. (1991) Scaled physical modeling of steam-injection experiments. J SPE Reservoir Eng 6(4):467-469

Kumar Ashish, Hassanzadeh Hassan (2021) A qualitative study of the impact of random shale barriers on SAGD performance using data analytics and machine learning. J Petrol Sci Eng 205:108950

Kumar Ashish, Hassanzadeh Hassan (2021) Impact of shale barriers on performance of SAGD and ES-SAGD-A review. Fuel $289: 119850$ 
Le Ravalec M, Morlot C, Marmier R, Foulon D (2009) Heterogeneity impact on SAGD process performance in mobile heavy oil reservoirs. Oil and Gas Sci Technol 64(4):469-476

Li W, Mamora D, Li Y, Qiu F (2011) Numerical investigation of potential injection strategies to reduce shale barrier impacts on SAGD process. J Can Pet Technol 50(03):57-64

Ma, Z., Leung, J.Y., 2018. Integration of data-driven models for characterizing shale barrier configuration in $3 \mathrm{D}$ heterogeneous reservoirs for SAGD operations. In: SPE Canada Heavy Oil Technical Conference. Society of Petroleum Engineers.

Pooladi DM, Mattar L (2002) SAGD Operations in the Presence of Overlying Gas Cap and Water Layer-Effect of Shale Layers. Petroleum Soc Canada. https://doi.org/10.2118/02-06-04

Shin H, Choe J (2009) Shale Barrier Effects on the SAGD Performance. Soc Petroleum Eng. https://doi.org/10.2118/125211-MS

Wang C, Leung J (2015) Characterizing the effects of lean zones and shale distribution in steam-assisted-gravity-drainage recovery performance. SPE Reservoir Eval Eng 18(03):329-345

Xia Y., Huang S., Chen X., Cao M., \& Yang L. (2018). Study on the Characteristics of Production Performance and Steam Chamber of SAGD Considering Interlayer. In SPE International Heavy Oil Conference and Exhibition. Society of Petroleum Engineers.

Yang G, Butler RM (1992) Effects of Reservoir Heterogeneities on Heavy Oil Recovery by Steam-Assisted Gravity Drainage. Petroleum Soc Canada. https://doi.org/10.2118/92-08-03

Zhang L, Li J, Sun L, Yang F (2020) An influence mechanism of shale barrier on heavy oil recovery using SAGD based on theoretical and numerical analysis. Energy 216:119099

Zhang Q, Liu H, Dong X, Liu Y, Li G, Wang Y (2020) A new comprehensive model to estimate steam chamber expansion and recovery performance of entire SAGD process. J Petrol Sci Eng 185:106629

Zheng J, Leung JY, Sawatzky RP, Alvarez JM (2018) A proxy model for predicting SAGD production from reservoirs containing shale barriers. J Energy Resour Technol Doi 10(1115/1):4041089

Zheng J, Leung JY, Sawatzky RP, Alvarez JM (2019) An AI-based workflow for estimating shale barrier configurations from SAGD production histories. Neural Comput Appl 31(9):5273-5297

Publisher's Note Springer Nature remains neutral with regard to jurisdictional claims in published maps and institutional affiliations. 